\title{
Pyelonephritis in adult women with homozygous sickle cell disease: about 42 cases
}

\author{
Sekongo Yassongui Mamadou ${ }^{1,2,3,{ }^{*}, \text { Abisse Agba }^{1} \text {, Tolo-Diebkile Aissata }}{ }^{2}$, Konan Sidoine ${ }^{1}$, \\ Kouamenan Sidonie ${ }^{1}$, Danho Nanho Clotaire ${ }^{2}$, Dora B. ${ }^{3}$, Siransy-Bogui Liliane ${ }^{1}$, \\ Kassougue Kadidia ${ }^{1}$, N'Guessan Koutoua Parfait ${ }^{1}$, Konate Seidou ${ }^{1}$, Galacteros F. ${ }^{1}$ \\ ${ }^{1}$ National Blood Transfusion Center (NBTC), Abidjan, Côte d'Ivoire \\ ${ }^{2}$ Clinical Hematology, Yopougon Teaching Hospital, Abidjan, Côte d'Ivoire \\ ${ }^{3}$ Genetic disease unit of red blood cell (UMGGR), Hospital Henri Mondor, Créteil, France
}

\section{Email address:}

sekyass@yahoo.fr (S. Y. Mamadou)

\section{To cite this article:}

Sekongo Yassongui Mamadou, Abisse Agba, Tolo-Diebkile Aissata, Konan Sidoine, Kouamenan Sidonie, Danho Nanho Clotaire, Dora B., Kassougue Kadidia, N'Guessan Koutoua Parfait, Konate Seidou, Galacteros F.. Pyelonephritis in Adult Women with Homozygous Sickle Cell Disease: about 42 Cases. American Journal of Internal Medicine. Vol. 2, No. 2, 2014, pp. 10-13.

doi: 10.11648/j.ajim.20140202.11

\begin{abstract}
Sickle cell disease is a condition with 3 parts of speech including infectious complications. They are essentially encapsulated bacterial organisms. There is a significant incidence of urinary infections to adults with sickle cell disease most particularly among women. The frequency and characteristics of pyelonephritis in women with sickle cell disease is poorly understood to this day, it seemed interesting to analyze over a period of one year, the profile of sickle cell patients followed in the genetic disease unit of red blood cell Hospital Henri Mondor, Créteil, and who took at least one episode of pyelonephritis. Patients and Methods: This study was conducted in the genetic disease unit of red blood cell (UMGGR) Hospital Henri Mondor in Créteil (France). This is a retrospective descriptive and analytical study on patients with homozygous sickle cell disease, females, aged 18 years or more. The selection was conducted over a period of one year from February 2007 to February 2008. Data were collected from medical records and from reports of record of each patient. We considered the clinical, paraclinical and therapeutic latest episode of pyelonephritis. Data processing was done using the software Statview. Results: The prevalence of pyelonephritis in women with sickle cell disease aged over 15 years was $6.12 \%$ annually. The median age at first episode of pyelonephritis was 23.5 years. The majority $(71.42 \%)$ was the first episode after 20 years. Among the factors predisposing to pyelonephritis, pregnancy has been implicated in $16.7 \%$ of cases. The symptoms of cystitis, with $52.4 \%$, were the fact favoring predominant. The average number episodes of pyelonephritis to our patients were 2 . The risk of recurrent pyelonephritis was significantly correlated statistically with the presence of cholelithiasis $(\mathrm{p}=0.04)$. Fever was the clinical symptoms that prompted the consultation in $95.24 \%$ cases. The consequences of sickle cell disease were important. We identified $16.7 \%$ cases of sepsis and $16.7 \%$ of worsening anemia requiring transfusion. The causative agent was E. coli in $85.7 \%$ of patients. $61.9 \%$ of patients received combination therapy. The intravenous therapy as first-line was found in $81 \%$. Fluoroquinolones were the molecules widely used in $71.4 \%$ of cases. The rate of clinical failure at 3 days of antibiotics was $4.76 \%$. The average time for obtaining apyrexia was 3 days. The average duration of treatment was 15 days. We observed no cases of death secondary to the episode of pyelonephritis. Conclusion: This preliminary work has highlighted the incidence of pyelonephritis in women adult with sickle cell and the the potential impact on sickle cell disease. Despite being underestimated because of the retrospective nature and short duration (1 year) of study, this frequency must motivate strategy to encourage more active educational preventive towards patients and early diagnosis of urinary tract infections to women with sickle cell disease.
\end{abstract}

Keywords: Pyelonephritis, Adult Women, Homozygous Sickle Cell Disease

\section{Introduction}

Sickle cell disease is an autosomal recessive disease caused by a single globin $\beta$ gene mutation, timely, located on chromosome 11 (11p 11-5).

It exists for sickle cell disease, different genotyps: homozygous SS (70\%), compound heterozygous SC (25\%), S beta thalassemia (5\%) asymptomatic subjects AS. 
It is a condition with three parts of speech: Chronic hemolytic anemia that can worsen, the vascular-occlusive complications: painful bone vascular-occlusive crises (VOC, ACS...), infectious complications: they are essentially encapsulated bacterial organisms. The risk of infection is high to children before 5 years but, to adults, it is the second leading cause of death after vascular-occlusive events [1].

There is a significant incidence of urinary tract infections and pyelonephritis in adulthood among the major sickle cell disease especially among women.

Pyelonephritis may result to vascular-occlusive complications, worsening of anemia, but also remote locations tanks into play with the prognosis especially during pregnancy (both maternal than fetal side), but also effects on the level of renal function.

The frequency and characteristics of pyelonephritis in women with sickle cell disease is poorly understood to this day, It seemed interesting to analyze over a period of one year, the profile of sickle cell patients followed in the genetic disease unit of red cells to the Hôpital Henri Mondor, Créteil (France), and who took at least one episode of pyelonephritis.

The overall objective of this work is to determine the characteristics of pyelonephritis in women with sickle cell disease most aged 18 years and over. Specifically, we attempt to clarify the factors influencing the recurrence and the impact on sickle cell disease.

\section{Patients and Methods}

This study was conducted in the genetic disease unit of red blood cell (UMGGR) Hospital Henri Mondor in Créteil (France).

This is a retrospective study of patients with homozygous sickle cell disease, females, aged 18 years or more, followed in the service of genetic diseases of red cell Henri Mondor Hospital.

The selection was conducted over a period of one year from February 2007 to February 2008: Data were collected from medical records and from reports of record of each patient.

We considered the clinical, paraclinical and therapeutic parameters of the latest episode of pyelonephritis.

All patients have benefited from the realization of a blood culture with antibiogram.

Data processing was done using the software Statview. We used the test khi2 in univariate analysis with a confidence interval at $95 \%$ and a significance threshold of $0.05 \%$

\section{Results}

The median age at first episode of pyelonephritis was 23.5 years. The majority of our patients $(71.42 \%)$ had the first episode after 20 years.

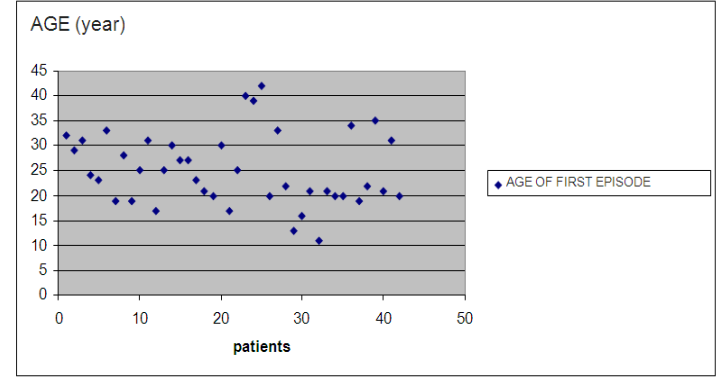

Figure 1. Age at first episode of pyelonephritis.

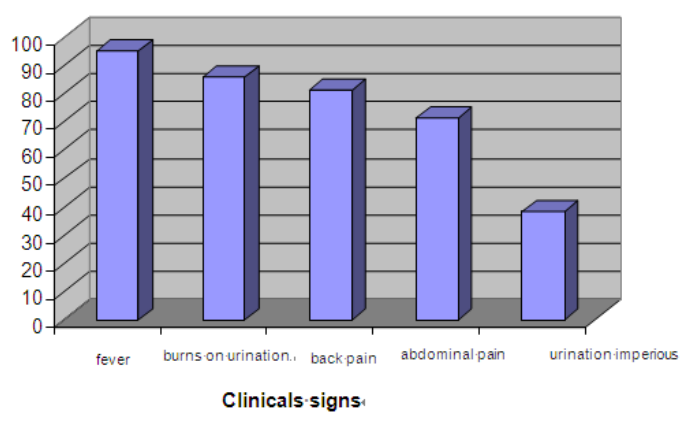

Figure 2. clinical signs of pyelonephritis.

Fever was the clinical symptoms that prompted the consultation in $95.24 \%$ cases, followed by burning urination in $85.7 \%$

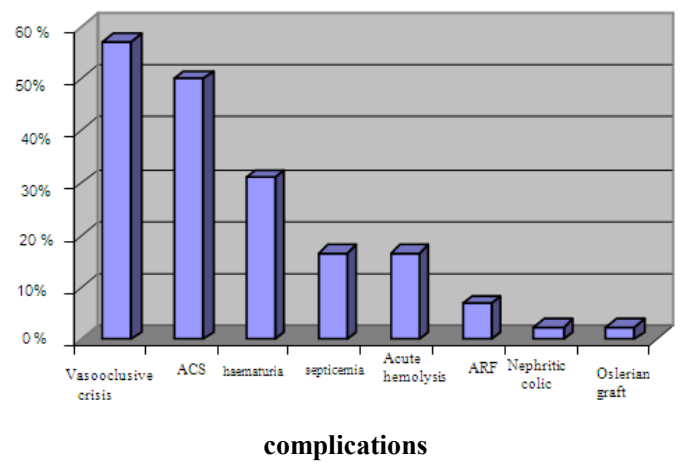

Figure 3. Complications observed.

ACS: Acute chest syndrome

ARF: Acure Renal Failure

Pyelonephritis have caused a vascular-oclusive crisis (VOC) in over half of our patients (57.1\% of cases), acute chest syndrome (ACS) in 50\% cases.

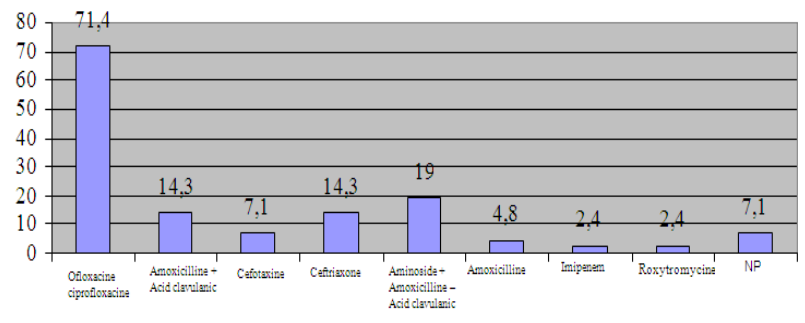

Figure 4. Antibiotic treatment. 
The molecules widely used were fluoroquinolones in $71.4 \%$ of cases. Aminosides in combination with Amoxicilline + Acid Clavulanic came in second with $19 \%$.

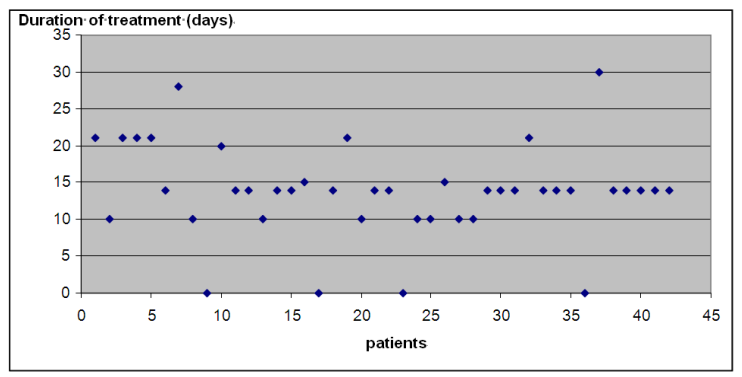

Figure 5. Duration of treatment.

The average duration of treatment was 15 days, with extremes of 10 days and 30 days. The majority of our patients were treated during 14 days

\section{Discussion}

In our study, we found over a period of 1 year, the prevalence of pyelonephritis to women with sickle cell disease aged over 18 years, $6.12 \%$. In the literature most studies do not distinguish acute pyelonephritis to the general framework of urinary tract infections [2]. The lack of available data did not allow us to compare our results.

In our series, the average age of our patients is 34 years with extremes of 22 years and 64 years. $78.57 \%$ had at least 1 pregnancy. For years, some medical teams advised against the occurrence of pregnancy to patients with sickle cell disease include major homozygotes [3]. With a life expectancy longer and improved quality of life, many patients now have access to motherhood. $[4,5]$

All patients had a history of urinary tract infections during follow-up. But because of susceptibility to infection in sickle cell disease, the incidence could be higher. Than in the general population, pyelonephritis is estimated at $20 \%$ per year among women in all age groups and $80 \%$ from 25 years [6].

The median age at first episode of pyelonephritis was 23.5 years. The majority of our patients $(71.42 \%)$ had the first episode after 20 years. Our results are in agreement with literature data. [5]. Because they are sexually active, patients who also had pregnancies could explain this fact. In the literature, sexual activity and pregnancy are described as factors implicated in the occurrence of pyelonephritis $[7,8,9]$.

Among the factors predisposing to pyelonephritis, pregnancy has been implicated in $16.7 \%$ of cases.

The symptoms of cystitis, with $52.4 \%$, was the predominant fact favoring.

The average episodes number of pyelonephritis among our patients was 2 with a maximum of 6 . Half of our patients have been only one episode. The risk of recurrent pyelonephritis is significantly correlated statistically with the presence of cholelithiasis $(\mathrm{p}=0.04)$. Indeed, 19 patients among the $42(45.24 \%)$ had a history of gallstones, and among them $13(68.42 \%)$ relapsed pyelonephritis against 6 $(35.58 \%)$ who did not make recidivism. Patients with major sickle cell disease and who have history of cholecystectomy, have a hemolytic profile (hemoglobin below) and a deficit in glucuronidation (free bilirubin higher). We therefore believe that this fact could influence the urinary $\mathrm{pH}$ and thus promote urinary tract infections. But this argument should be verified by a prospective study.

Fever was the clinical symptoms that prompted the consultation in $95.24 \%$ cases, followed by burning urination in $85.7 \%$, back pain in $81 \%$ of cases, abdominal pain in $71.4 \%$ of cases. The clinical picture of pyelonephritis in the sickle cell is not different from that of the general population [10].

The consequences of sickle cell disease were important. These pyelonephritis have caused a vascular-occlusive crisis (VOC) in over half of our patients (57.1\% of cases), acute chest syndrome (ACS) in $50 \%$ of cases.

We identified $16.7 \%$ of all cases of sepsis due to E. coli and also $16.7 \%$ of worsening anemia requiring transfusion.

In the literature sepsis due to pyelonephritis are about $20 \%[9,10,11]$. We believe that our figure is underestimated because of the retrospective nature of our study.

In the sickle cell disease, E. coli sepsis generally represents $12.7 \%$ [2].

Among the 7 pregnant women, pyelonephritis has trained two stillbirths and spontaneous miscarriages. We did not find in medical records, the period during which pregnancy occurred to these 3 events. It is clearly established that the pyelonephritis in pregnant women has an impact on fetal outcome [5]. But this risk is difficult to assess because these women are no current register for these patients, it varies from study to study. Howard RJ et al [12] and D Poddar et al [13] found high rates of $10 \%$ to $24 \%$ while D Stefanescu [14] does not relate to increased risk compared with that of the general population.

$31 \%$ of patients had hematuria. This incidence is higher than that reported in the literature for the general population. We believe that the hematuria is not only due to pyelonephritis in the sickle, because it is a complication frequently found [15]. It follows myocardial microthrombotiques with extravasation of blood in the inner medulla and renal papilla, middle seats of a hypertonic relatively hypoxic [16]. We noted that there were two cases of acute renal failure (ARF) and one case of graft oslerian on rheumatic valvuloplasty.

On the ultrasound, 5 patients (11.9\%) had a renal abscess, 2 papillarys necrosis and 2 other dilated pyelocalicielle cavities. The majority of patients (76.2\%) had normal renal morphology on ultrasound. 2 patients who have sepsis had a renal abscess. Our results are in agreement with literature data $[15,17]$.

The causative agent was E. coli in $85.7 \%$ of patients. The urinary cultures were sterile in 2 patients who had taken antibiotics less than 24 hours at home before admission. $16.7 \%$ of blood cultures returned positive for E. coli. It is the causative 
organism in all series in nearly $85 \%$ of cases $[8,12,14,15]$.

The majority of our patients have been supported in an emergency department in the early events.

The average time elapsed between the onset and consultation as noted throughout the medical records was $48 \mathrm{~h}$.

$61.9 \%$ of patients received combination therapy against $31 \%$ of monotherapy. The intravenous therapy as first-line is found in $81 \%$ of cases against $19 \%$ of oral treatment. The molecules widely used were fluoroquinolones in $71.4 \%$ of cases. Aminosides in combination with Amoxicilline + Acid Clavulanic came in second with $19 \%$. Our results corroborate those of De Pont AC et al. [9]. We believe that this is a field subject to multiple complications; this has guided the choice of antibiotic therapy. This therapeutic approach is consistent with the guidelines of the "Infectious Disease Society of America", where monotherapy with a fluoroquinolone is recommended as first-line patients with uncomplicated pyelonephritis and dual therapy in combination with aminosides in case of complications.

We noted 2 cases of pyelonephritis to E. coli resistant to fluoroquinolones including 1 case treated with imipenem. The rate of clinical failure at 3 days of antibiotic therapy, observed in our series $(4.76 \%)$ is superimposed on that found in the literature [11]. The average time for obtaining apyrexia was 3 days similar to literature data in the general population [15]

The average duration of treatment was 15 days, with extremes of 10 days and 30 days. The majority of our patients were treated during 14 days. This is in agreement with literature data $[13,14,15]$.

We observed no cases of death secondary to the episode of pyelonephritis. The speed of care could explain the absence of adverse developments.

\section{Conclusion}

This preliminary work has highlighted the incidence of pyelonephritis to women adult with sickle cell disease and the potential impact on sickle cell disease.

Pyelonephritis to adult women with sickle cell disease is responsible for severe vaso-oclusive crisis with acute chest syndrome. It leads a risk of spontaneous abortion during the pregnancy. The treatment need hospitalization and based on association of antibiotic therapy dominated by fluoroquinolones.

Despite being underestimated because of the retrospective nature and short duration (1 year) of our study, this frequency should encourage a more active preventive educational strategy towards patient (there are books on the conduct taken to prevent urinary tract infections) and early diagnosis of urinary tract infections.

\section{Acknowledgments}

We thank Dr. Dora Bachir to UMGGR of hospital henry mondor of creteil for her active contribution to this work and Pr Catherine Cordonier of clinical hematology service of henry mondor for her advice.

\section{References}

[1] Zarouk V., P. Lesprit. Infection in adult with sickle cell disease. In The Sickle Cell Disease, 2003 : 117-123

[2] Zarrouk V., Habibi A., Zahar Jr., Roubot-Thoraval F., Bachir D., et al. Bloodstream infection in adults with Sickle Cell Disease. Association with venous cathethers, staphylococcus aureus, and bone-joint infections. Med. 2006, 85; 1: 43-47.

[3] Fort A, Morrisson J, Borreras L, Diggs L, Fish S. conseling the patient with sickle cell disease about reproduction: pregnancy outcome does not justify the maternal risk. Am J Obstet Gynecol 1971; 111: 324-7.

[4] Rust Oa. Pregnancy complicated by sickle hemoglobinopathy. Clin Obstet Gunecol 1995; 38: 462-84.

[5] Sun Pm, Wilburn W, Raynor Bd, Jamieson D. sickle cell disease in pregnancy: twenty years of experience at grady Memorial Hospital, Atlanta, Geaorgia. Am J Obstet Gynecol. 2001; 184: 1127-30.

[6] Vidal Recos. Acute pyelonephritis in adults. www.vidalrecos.fr/pages/reco.php?defche $=153187$

[7] Leborgne-Samuel Y, Kadhel P, Ryan C, Vendittelli F. Sickle cell disease and pregnancy. Rev Prat 2004, 30 ; 54 : 157882

[8] Bruni D, Wigfall Dr, Zimmerman Sa, Rasoff Pm, Wiener Js. Genitourinary complications of sickle cell disease. J Urol 2001, 166; 3 803-11

[9] De Pont Ac, Wolf H, Van Delden Om, De Reijke Tm. Pyelonephritis during pregnancy: a threat to mother and child. Ned TTijdschr Geneeskd 2008, 5; 152: 58.

[10] Meyrier Alain Pyélonéphrites aiguës: infections of the urinary tract. Rev Prat 2003, $53 ; 16: 1777-84$.

[11] Acute pyelonephritis. Randomised double-blind comparison of ciprofloxacin and tobramycin. www.spc.univlyon.fr/lecture-

critique/TP/travail_sur_article/infection_urinaire/article.htl $\mathrm{m}-20 \mathrm{k}$

[12] Howard Rj. Management of sickling conditions in pregnancy. Br J Hosp Med 1996; 56: 7 - 10.

[13] Podard D, Maude G, Plant M, Scorer H, Serjeant G. Pregnancy in Jamaican women with homozygous sickle cell disease. Fetal and maternal outcome. Br J Obstet Gynecol 1986; 93: 927-32.

[14] Stefanescu D. Sickle cell disease and pregnancy. Doctorat Thesis. Université René-Descartes (Paris VI) 2001 : 11.

[15] Anonymous. Hemoglobinopathies in pregnancy. Int $\mathrm{J}$ Gynecol Obstet $1993 ; 43: 333-42$.

[16] Ataga Ki, Orringer Ep. Renal abnormalities in sickle cell disease. Am J Hematol. 2000; 63: 205-11.

[17] Remy P. Renal complications of sickle cell disease. In La Drépanocytose, 2003 : 117-123 